\title{
Desenvolvimento de porta-enxerto de goiabeira sob irrigação com água salinizadas e doses de nitrogênio*
}

\section{Rootstock of guava development under irrigation with salted water and nitrogen levels*}

\author{
Leandro de Pádua Souza ${ }^{1}$, Reginaldo Gomes Nobre ${ }^{2}$, Evandro Manoel da Silva ${ }^{3}$, Fablo Fernandes de Sousa ${ }^{4}$, Israel Almeida \\ da Silva
}

\begin{abstract}
Resumo: Os efeitos dos sais nos solos, causando variações na estrutura, permeabilidade e aeração do solo, afetam indiretamente o crescimento das plantas. Desta forma o incremento da dosagem de nitrogênio, como fator isolado, pode promover melhor eficiência na produção de mudas. Neste sentido, objetivou-se com este trabalho, analisar a influência da salinidade da água de irrigação associada a doses crescentes de nitrogênio sobre o desenvolvimento de porta-enxerto de goiabeira de genótipo 'Crioula'. O experimento foi conduzido em tubetes sob condições de ambiente protegido no CCTA/UFCG. Utilizou-se o delineamento experimental em blocos casualizados, com os tratamentos dispostos em esquema fatorial 5 x 4, correspondentes a cinco níveis de condutividade elétrica da água - CEa $\left(0,3 ; 1,1 ; 1,9 ; 2,7\right.$ e $\left.3,5 \mathrm{dS} \mathrm{m}^{-1}\right)$ e quatro doses de nitrogênio (70, 100, 130 e 160\% de $\mathrm{N}$ da dose recomendada para cultivo de mudas de goiabeira cv. Paluma) com 4 repetições e 5 plantas por parcela. Não houve interação significativa entre os fatores salinidade da água de irrigação e adubação nitrogenada sob o crescimento de porta-enxerto de goiabeira de genótipo "Crioula". O aumento da CEa a partir de $0,3 \mathrm{dS} \mathrm{m}^{-1}$ afeta negativamente e de forma linear o diâmetro do caule (DC), número de folhas (NF), taxa de crescimento absoluto (TCAap) e relativo da altura de planta (TCRap), o equilíbrio de crescimento altura de planta/ diâmetro do caule e a exportação de massa seca da folha para o resto da planta (RMF). A dose de $70 \%$ de $\mathrm{N}\left(541,1 \mathrm{mg} \mathrm{de} \mathrm{N} \mathrm{dm}^{-1}\right.$ de solo) proporciona maiores valores do DC, NF, TCAap e TCRap de porta-enxerto de goiabeira "Crioula".
\end{abstract}

Palavras-chaves: Psidium guajava L., nutrição de plantas, condutividade elétrica.

\begin{abstract}
The effects of salts in the soil, causing variations in structure, permeability and aeration of the soil indirectly affect the growth of plants. Thus the increased nitrogen dosing as an isolated factor, can promote greater efficiency in the production of seedlings. In this sense, the aim of this work was to analyze the influence of irrigation water salinity associated with increasing doses of nitrogen on the development of rootstock of guava genotypes 'Crioula'. The experiment was conducted in plastic pots under greenhouse conditions in the CCTA / UFCG. We used the experimental randomized block design, with the treatments in a factorial $5 \times 4$, corresponding to five levels of electrical conductivity of the water - CEa $(0.3,1.1,1.9,2.7$ and $\left.3.5 \mathrm{dS} \mathrm{m}^{-1}\right)$ and four nitrogen rates $(70,100,130$ and $160 \%$ of the recommended dose $\mathrm{N}$ for guava cultivation seedlings cv. Paluma) with 4 replications and 5 plants per plot. There was no significant interaction between the factors salinity of irrigation water and nitrogen fertilization on growth rootstock genotype of guava "Crioula". Increased CEa from $0.3 \mathrm{dS} \mathrm{m}^{-1}$ affects negatively and linearly stem diameter (DC), number of leaves (NF), absolute growth rate (TCAAP) and relative plant height (TCRap), the height growth balance of plant / stem thickness and dry mass export of the sheet for the rest of the plant (RMF). The dose of $70 \%$ of $\mathrm{N}\left(541.1 \mathrm{mg} \mathrm{N} \mathrm{dm}^{-1}\right.$ soil) provides higher values of DC, NC, TCAap and TCRap rootstock of guava "Crioula".
\end{abstract}

Key words: Psidium guajava L., plant nutrition, electrical conductivity.

\footnotetext{
*Autor para correspondência

Recebido para publicação em 09/03/2015; aprovado em 14/05/2015

*Trabalho faz parte da dissertação do primeiro autor, financiado pelo CNPq edital Universal.

${ }^{1}$ Eng. Agrônomo, Pós-graduando em Horticultura Tropical, Centro de Ciências e Tecnologia Agroalimentar, Universidade Federal de Campina Grande, CEP 58015-570 Pombal, PB, Fone (87) 96373266. E-mail: engenheiropadua@ hotmail.com,

${ }^{2}$ Prof. Doutor Adjunto III CCTA/ UAGRA/UFCG, Pombal, PB. E-mail: rgomesnobre@pq.cnpq.br;

${ }^{3}$ Eng. Agrônomo, Mestre em Horticultura Tropical. Pombal, PB. E-mail: evandroagroman@hotmail.com

${ }^{4}$ Graduando em Agronomia, CCTA/UFCG, Pombal, PB. E-mail: fablofernandes@ hotmail.com; israelfla81@gmail.com;
} 


\section{INTRODUÇÃO}

A goiabeira (Psidium guajava L.) é uma fruteira disseminada em regiões de clima tropical e subtropical, o que caracteriza ser uma planta rústica com possibilidade de se adaptar em diferentes condições edafoclimáticas (CAVALCANTE et al., 2010). É espécie relativamente resistente à seca, exige temperatura média anual superior a 22 ${ }^{\circ} \mathrm{C}$ e se adapta melhor em solos arenoargilosos, profundos, bem drenados, com faixa de pH entre 5,0 e 6,5 (GONZAGA NETO, 2001). Na fase de muda, é classificada como sensível à salinidade, com uma salinidade limiar de $1,2 \mathrm{ds} \mathrm{m}^{-1}$ (TÁVORA et al., 2001).

Apesar da expressividade da irrigação na produção de frutíferas em geral, nas regiões semiáridas, onde a evapotranspiração supera a pluviosidade, a salinidade do solo e da água de irrigação se constitui num grande obstáculo ao sistema de produção (FREIRE et al., 2010).

De acordo com Ayers e Westcot (1999) qualquer que seja sua fonte, a água utilizada na irrigação sempre contém sais que, em geral, variam expressivamente em qualidade e quantidade. E o uso de água de qualidade inferior, associado ao manejo do sistema solo-água-planta, e à deficiência do sistema de drenagem, contribuem com a salinização dos solos nas áreas irrigadas.

Segundo Gomes et al. (2005), a salinidade causa efeitos osmóticos e tóxicos nas plantas pela atividade dos íons $\mathrm{Na}^{+} \mathrm{e} \mathrm{Cl}^{-}$, afetando muitos aspectos do metabolismo da planta, como reduções na transpiração, fotossíntese, translocação, respiração, desequilíbrio iônico e ou hídrico, que reflete diretamente no crescimento e na produção das culturas.

Estudos têm demonstrado que a irrigação de mudas de goiabeira com águas salinas causam efeitos depressivos sobre o crescimento e desenvolvimento das plantas, incluindo a altura de plantas, diâmetro do caule, número de folhas e acúmulo de fitomassa e a atividade fotossintética (TÁVORA et al., 2001; CAVALCANTE et al., 2007; CAVALCANTE et al., 2010).

Para Cavalcante et al. (2007) a formação de mudas de goiabeira, na região semiárida do Nordeste, onde as águas nem sempre são de boa qualidade, está na dependência do uso de técnicas que viabilizem o manejo do solo e da água com teor elevado de sais. Flores et al. (2001) reportam que a adubação nitrogenada constitui uma das técnicas que pode reduzir os efeitos da salinidade nas plantas. Sobretudo são escassos trabalhos avaliando a interação destes fenômenos na cultura da goiabeira.

$\mathrm{O}$ nitrogênio caracteriza-se como o segundo nutriente mais exigido pela cultura da goiabeira na fase inicial de desenvolvimento (FRANCO et al., 2007). Estudos têm demonstrado que o incremento da dosagem de nitrogênio, como fator isolado, pode promover melhor eficiência na produção de mudas da espécie (FRANCO et al., 2007; DIAS et al., 2012),

Neste sentido, objetivou-se com este trabalho, analisar a influência da salinidade da água de irrigação associada a doses crescentes de nitrogênio sobre o desenvolvimento de porta-enxerto de goiabeira de genótipo 'Crioula'.

\section{MATERIAL E MÉTODOS}

O trabalho foi desenvolvido no ano de 2014, em casa de vegetação do Centro de Ciências e Tecnologia Agroalimentar da Universidade Federal de Campina Grande (CCTA/UFCG), Campus de Pombal-PB, cujas coordenadas geográficas locais de referência são $6^{\circ} 48^{\prime} 16^{\prime \prime} \mathrm{S}, 37^{\circ} 49^{\prime} 15^{\prime \prime} \mathrm{O}$ e altitude média de $144 \mathrm{~m}$.

Utilizou-se o delineamento experimental em blocos casualizados, com os tratamentos dispostos em esquema fatorial $5 \mathrm{x} 4$, correspondentes a cinco níveis de condutividade elétrica da água - CEa $(0,3 ; 1,1 ; 1,9 ; 2,7$ e 3,5 $\left.\mathrm{dS} \mathrm{m}^{-1}\right)$ e quatro doses de nitrogênio $(70,100,130$ e $160 \%$ de $\mathrm{N}$ ), com 4 repetições e 5 plantas por parcela. As doses de $\mathrm{N}$ foram determinadas com base na dose de $100 \%$ de $\mathrm{N}$ equivalente a $773 \mathrm{mg} \mathrm{de} \mathrm{N} \mathrm{dm}^{-1}$, conforme recomendação de Dias et al. (2012) para a produção de mudas de goiabeira cv. Paluma em sacolas de polietileno de 1,2 L.

Os níveis de salinidade das águas foram obtidos mediante a adição na água de abastecimento local (CEa de 0,3 $\left.\mathrm{dS} \mathrm{m}^{-1}\right)$ dos seguintes sais: cloreto de sódio $(\mathrm{NaCl})$, cloreto de cálcio $\left(\mathrm{CaCl}_{2} \cdot 2 \mathrm{H}_{2} \mathrm{O}\right)$ e cloreto de magnésio $\left(\mathrm{MgCl}_{2} \cdot 6 \mathrm{H}_{2} \mathrm{O}\right)$, na proporção de 7:2:1, relação esta predominante nas principais fontes de água disponíveis para irrigação no Nordeste brasileiro (MEDEIROS, 1992), obedecendo-se a relação entre $\mathrm{CEa}$ e a concentração dos sais $\left(\mathrm{mmol}_{\mathrm{c}} \mathrm{L}^{-1}=\mathrm{CE} \times 10\right)$ (RHOADES et al., 2000).

Foi utilizado sementes de um genótipo de goiabeira considerado "Crioula" de propriedades rurais do município de Pombal-PB, o qual bem adaptado às condições edafoclimáticas locais.

O semeio foi realizado em 18 de março de 2014, em tubetes usando-se quatro sementes por tubete, na profundidade de $1,0 \mathrm{~cm}$. O experimento foi instalado em tubetes plásticos com dimensões de $19 \mathrm{~cm}$ de altura e $6,3 \mathrm{~cm}$ de diâmetro, capacidade $288 \mathrm{~cm}^{-3}$, e abertura na parte inferior para permitir livre drenagem. Estes recipientes foram dispostos em bandejas com capacidade para 54 tubetes, apoiadas em bancadas metálicas (cantoneiras), a uma altura de $0,8 \mathrm{~m}$ do solo. Após as plântulas apresentarem dois pares de folhas verdadeiras totalmente expandidas, realizou-se o desbaste, deixando-se apenas uma plântula por tubete, a de melhor vigor.

No preenchimento dos tubetes foi utilizado substrato composto de Neossolo flúvico + areia + esterco bovino curtido, na proporção de 82,15 e $3 \%$, respectivamente, cujas características físicas e químicas (Tabela 1), foram analisadas no Laboratório de Solos e Planta do CCTA/UFCG obtidas conforme Claessen (1997). 
Tabela 1. Características físicas e químicas do substrato utilizado no experimento

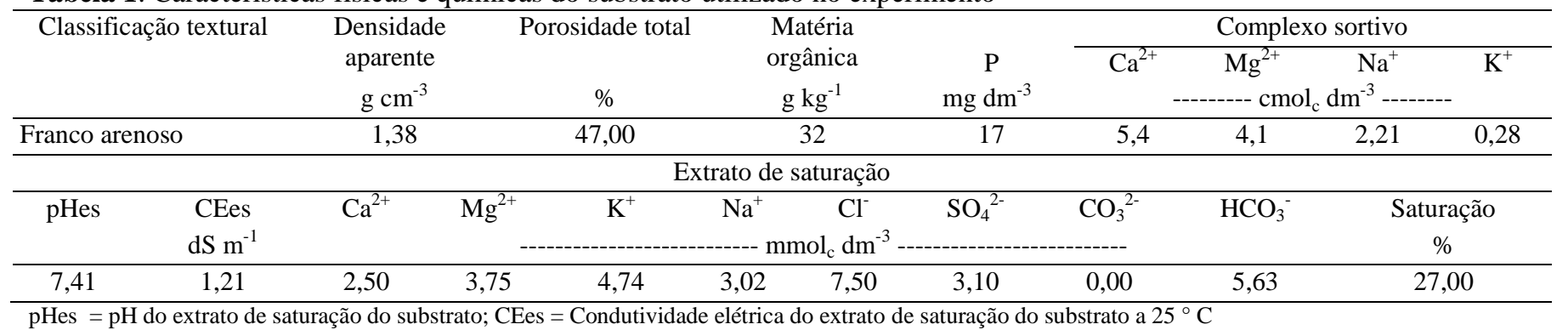

A aplicação das águas salinas teve início aos 25 dias após a emergência de plântulas (DAE). As irrigações com uso dessas águas foram feitas, conforme o tratamento, com base na necessidade hídrica da planta, pelo processo de lisimetria de drenagem, sendo aplicado diariamente o volume retido no tubete, determinado pela diferença entre o volume aplicado e volume drenado da irrigação anterior. As irrigações foram feitas duas vezes ao dia, sendo no início da manhã e final da tarde. Aplicou-se a cada quinze dias, uma fração de lixiviação de $15 \%$ com base no volume aplicado neste período, de modo a reduzir a salinidade do extrato de saturação do substrato.

A adubação nitrogenada iniciou-se juntamente com aplicação das águas salinas, ou seja, aos 25 DAE, dividida em 14 aplicações em partes iguais, sendo realizadas semanalmente, utilizando-se como fonte de nitrogênio a ureia (45\% de N), aplicada via fertirrigação com água de condutividade elétrica de $0,3 \mathrm{dS} \mathrm{m}^{-1}$ para todos os tratamentos.

O desenvolvimento do porta-enxerto de goiabeira foi avaliado através do diâmetro de caule (DC) e número de folhas (NF) aos 85 e 160 dias após a emergência (DAE), relação altura/diâmetro do caule (AP/DC) e razão de massa da folha (RMF) aos 190 DAE e taxa de crescimento absoluto de altura de plantas (TCAap) e relativo de altura de planta (TCRap) no período de 25-130 DAE.

O DC foi medido a $5 \mathrm{~cm}$ do colo da planta. A determinação do NF foi feita pela contagem das folhas que estavam com o limbo foliar totalmente aberto.

A AP/DC foi mensurada mediante a relação entre a altura de plantas e diâmetro do caule, enquanto que a RMF foi determinada pela relação entre a massa seca de folhas e massa seca total de planta,

A TCAap e TCRap foram determinadas de acordo com metodologia descrita por Benincasa (2003), conforme as Eq. 1 e 2 .

$$
\begin{aligned}
\text { TCAdc } & =\frac{\left(\mathrm{AP}_{2}-\mathrm{AP}_{1}\right)}{\left(\mathrm{t}_{2}-\mathrm{t}_{1}\right)} \\
\text { TCRdc } & =\frac{\left(\ln \mathrm{AP}_{2}-\ln \mathrm{AP}_{1}\right)}{\left(\mathrm{t}_{2}-\mathrm{t}_{1}\right)}
\end{aligned}
$$

Em que:

TCAap = taxa de crescimento absoluto da altura de planta $\left(\mathrm{cm} \mathrm{dia}{ }^{-1}\right)$;
TCRap $=$ Taxa de crescimento relativo da altura de planta $\left(\mathrm{cm} \mathrm{cm}^{-1} \mathrm{dia}^{-1}\right)$;

AP1 $=$ altura de planta $(\mathrm{cm})$ no tempo $t_{1}$;

$\mathrm{AP}_{2}=$ altura de planta $(\mathrm{cm})$ no tempo $\mathrm{t}_{2}$;

$\mathrm{DC}_{1}=$ diâmetro do caule $(\mathrm{mm})$ no tempo $\mathrm{t}_{1}$;

$\mathrm{DC}_{1}=$ diâmetro do caule $(\mathrm{mm})$ no tempo $\mathrm{t}_{2}$;

$\ln =$ logaritmo natural.

Os dados obtidos foram avaliados mediante análise de variância pelo teste $\mathrm{F}$ em nível de 0,05 e 0,01 de probabilidade e nos casos de significância, realizou-se análise de regressão linear e polinomial quadrática, utilizando-se do software estatístico SISVAR/UFLA.

\section{RESULTADOS E DISCUSSÃO}

Conforme o resumo da análise de variância (Tabela 2) observa-se que não houve interação significativa entre os fatores salinidade da água de irrigação x doses de nitrogênio (S x DN) sobre as variáveis estudas. Outrossim, constatou-se efeito significativo isolado $(\mathrm{p}<0,01)$ da salinidade da água de irrigação e doses de nitrogênio sobre diâmetro de caule (DC) aos 85 e 160 dias após a emergência (DAE). Para o número de folhas (NF) verifica-se que ocorreu apenas efeito significativo $(\mathrm{p}<0,01)$ da salinidade da água de irrigação aos 85 DAE e para as doses de nitrogênio aos 160 DAE.

Tabela 2: Resumo da análise de variância para diâmetro de caule (DC) e número de folhas (NF) de porta-enxerto de goiabeira genótipo Crioula irrigada com águas salinizadas e sob adubação nitrogenada, aos 85 e 160 dias após a emergência - DAE.

\begin{tabular}{lccccc}
\hline \multirow{2}{*}{$\begin{array}{c}\text { Fonte de } \\
\text { variação }\end{array}$} & \multicolumn{4}{c}{ Quadrado médio } \\
\cline { 2 - 6 } & GL & \multicolumn{2}{c}{ DC } & \multicolumn{2}{c}{ NF } \\
\cline { 2 - 6 } & \multicolumn{2}{c}{85} & 160 & 85 & 160 \\
\hline Salinidades (S) & 4 & $0,147^{* *}$ & $0,453^{* *}$ & $32,906^{* *}$ & $7,318^{\mathrm{ns}}$ \\
Reg. linear & 1 & $0,507^{* *}$ & $1,532^{* *}$ & $120,06^{* *}$ & $4,489^{\mathrm{ns}}$ \\
Reg. quadrática & 1 & $0,075^{\mathrm{ns}}$ & $0,033^{\mathrm{ns}}$ & $2,701^{\mathrm{ns}}$ & $10,631^{\mathrm{ns}}$ \\
Doses de N (DN) & 12 & $0,147^{* *}$ & $1,059^{* *}$ & $1,131^{\mathrm{ns}}$ & $168,106^{* *}$ \\
Reg. linear & 1 & $0,428^{* *}$ & $3,111^{* *}$ & $2,608^{\mathrm{ns}}$ & $492,618^{* *}$ \\
Reg. quadrática & 1 & $0,0003^{\mathrm{ns}}$ & $0,055^{\mathrm{ns}}$ & $0,666^{\mathrm{ns}}$ & $10,296^{\mathrm{ns}}$ \\
S*DN & 12 & $0,023^{\mathrm{ns}}$ & $0,065^{\mathrm{ns}}$ & $2,813^{\mathrm{ns}}$ & $9,687^{\mathrm{ns}}$ \\
Bloco & 3 & $0,015^{\mathrm{ns}}$ & $0,005^{\mathrm{ns}}$ & $2,154^{\mathrm{ns}}$ & $5,896^{\mathrm{ns}}$ \\
CV (\%) & & 7,53 & 6,75 & 16,85 & 26,78 \\
\hline
\end{tabular}

$\mathrm{ns}, * *, *$ respectivamente não significativos, significativo a $\mathrm{p}<0,01$ e $\mathrm{p}<$ 0,05 
O fator salinidade da água de irrigação afetou negativamente o diâmetro caulinar aos 85 e 160 DAE (Figura 1A). Conforme as equações de regressão (Figura 1A) o modelo linear indica decréscimo de $2,45 \%$ e $3,04 \%$ no DC por aumento unitário da $\mathrm{CEa}$, ou seja, redução de $9,82 \% \quad(85$ DAE) e $12,16 \%$ (160 DAE) no diâmetro das plantas irrigadas com água de $3,5 \mathrm{dS} \mathrm{m}^{-1}$ em relação as submetidas a $0,3 \mathrm{dS} \mathrm{m}$

1 . Constata-se que o efeito mais drástico ocorreu aos 160 DAE, possivelmente, devido o maior tempo de exposição das plantas à salinidade.

Segundo Rhoades et al. (2000), o excesso de sais na zona radicular das plantas exerce efeitos nocivos ao crescimento, em virtude do maior efeito osmótico externo à raiz e restrição ao fluxo de água do solo para as plantas, que afeta a turgescência das células, e consequentemente, o crescimento e a divisão celular.

Em relação às doses de nitrogênio, verifica-se pelas equações de regressão (Figura $1 \mathrm{~B}$ ) diminuições sobre o DC de $2,70 \%$ e $4,80 \%$ (85 e 160 DAE, respectivamente) por aumento de $30 \%$ da dose de $\mathrm{N}$, ou seja, declínio de $0,19 \mathrm{~mm}$ $(8,10 \%)$ e $0,53 \mathrm{~mm}(22,59 \%)$ no DC das plantas adubadas com a dose de $160 \%$ de $\mathrm{N}\left(1237 \mathrm{mg}\right.$ de $\left.\mathrm{N} \mathrm{dm}^{-3}\right)$ em comparação com as que receberam $70 \%$ de N (541 mg de N $\left.\mathrm{dm}^{-3}\right)$.

Conforme Oliveira et al. (2009), elevados teores de adubação nitrogenada podem proporcionar desbalanço entre nutrientes no solo e, em consequência, redução no crescimento, desenvolvimento e produção das culturas.

Figura 1: Diâmetro do caule - DC de porta-enxerto de goiabeira Crioula em função da salinidade da água de irrigação - CEa (A) e doses de nitrogênio (B) aos 85 e 160 dias após a emergência -DAE.
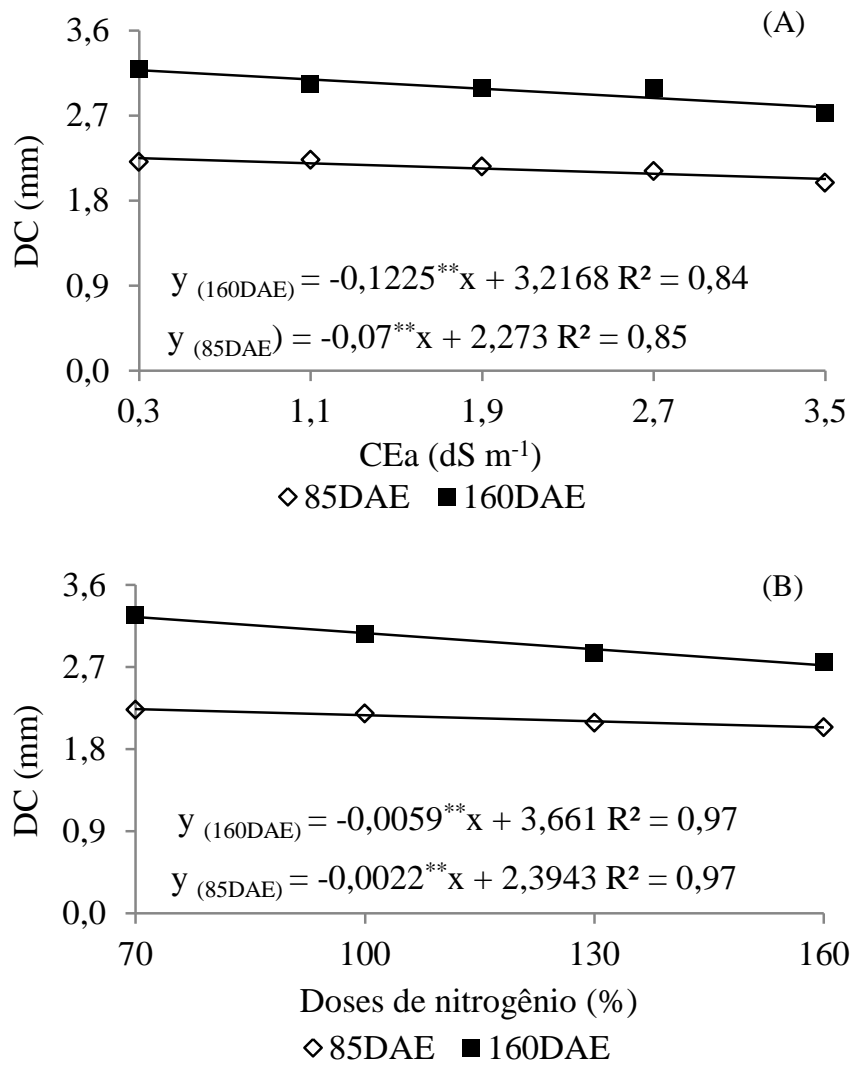

O aumento da salinidade da água de irrigação proporcionou efeito linear decrescente para variável número de folhas aos 85 DAE (Figura $2 \mathrm{~A}$ ), que segundo equação de regressão, a redução por aumento unitário da $\mathrm{CEa}$ foi de $8,35 \%$, ou seja, as plantas que foram irrigadas com a condutividade mais elevada $\left(3,5 \mathrm{dS} \mathrm{m}^{-1}\right)$ apresentaram diminuição de $26,72 \%$ (3,4 folhas por planta).

A redução do número de folhas em função da salinidade da água de irrigação constitui um processo fisiológico de adaptação das plantas ao estresse salino, como forma de reduzir a perda de água por transpiração (SIQUEIRA et al., 2005).

De acordo com a equação de regressão (Figura $2 \mathrm{~B}$ ), nota-se para o fator doses de nitrogênio que o NF aos 160 DAE apresentou redução linear de $11,40 \%$ para cada incremento de $30 \%$ de N. Nas plantas submetidas à dose de $160 \%$ de N observa-se que houve uma diminuição de $34,20 \%$ quando comparadas as plantas que receberam a dose de $70 \%$ de N.

Figura 2: Número de folhas - NF de porta-enxerto de goiabeira Crioula em função da salinidade da água de irrigação - CEa aos 85 dias após a emergência - DAE (A) e adubação nitrogenada aos 160 DAE (B).
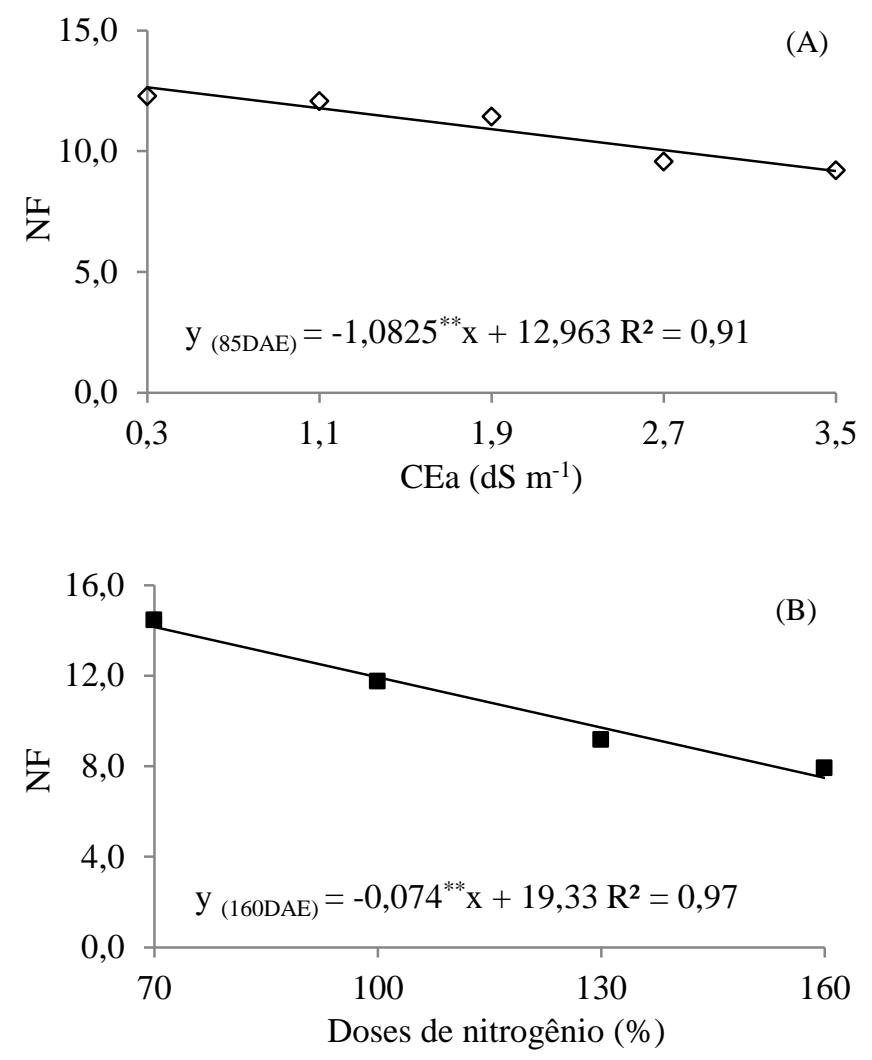

Com base no resumo da análise de variância (Tabela $2)$, observa-se que houve efeito significativo isolado $(\mathrm{p}<0,01)$ dos fatores salinidade da água de irrigação e doses de nitrogênio sobre a taxa de crescimento absoluto (TCAap) e relativo da altura de planta (TCRap) no intervalo de 25 a 130 DAE. Para a razão de massa da folha (RMF) e relação altura/diâmetro do caule (AP/DC) aos 190 DAE, constata-se que houve efeito significativo $(p<0,01)$ apenas do fator salinidade da água de irrigação. Outrossim, verifica-se que 
não houve interação significativa entre os fatores salinidade variáveis estudas.

da água de irrigação x doses de nitrogênio $(\mathrm{S} \times \mathrm{DN})$ sobre as

Tabela 3: Resumo da análise de variância para taxa de crescimento absoluto (TCAap) e relativo da altura de planta (TCRap) no período de 25 a 130 dias após a emergência - DAE e, razão de massa da folha (RMF) e relação altura/diâmetro do caule (AP/DC) aos 190 DAE de porta-enxerto de goiabeira de genótipo Crioula irrigada com águas salinizadas e sob adubação nitrogenada

\section{Quadrado médio}

Fonte de variação

GL

\begin{tabular}{|c|c|c|c|c|c|}
\hline & & TCAap & TCRap & $\mathrm{RMF}$ & AP/DC \\
\hline & & $25-130$ & $25-130$ & 190 & 190 \\
\hline$\overline{\text { Salinidades (S) }}$ & 4 & $0,003^{* *}$ & $0,000007^{* *}$ & $0,021^{* * *}$ & $7,387^{* * *}$ \\
\hline Reg. linear & 1 & $0,012^{* *}$ & $0,00002^{* *}$ & $0,076^{* *}$ & $25,624^{* *}$ \\
\hline Reg. quadrática & 1 & $0,001^{\mathrm{ns}}$ & $0,000001^{\mathrm{ns}}$ & $0,0009^{\mathrm{ns}}$ & $0,141^{\mathrm{ns}}$ \\
\hline Doses de N (DN) & 3 & $0,006^{* *}$ & $0,00001^{* *}$ & $0,007^{\mathrm{ns}}$ & $2,458^{\mathrm{ns}}$ \\
\hline Reg. linear & 1 & $0,020^{* *}$ & $0,00002^{* *}$ & $0,006^{\mathrm{ns}}$ & $1,151^{\mathrm{ns}}$ \\
\hline Reg. quadrática & 1 & $0,0001^{\mathrm{ns}}$ & $0,000001^{\mathrm{ns}}$ & $0,001^{\mathrm{ns}}$ & $6,160^{\mathrm{ns}}$ \\
\hline Interação $(\mathrm{S} * \mathrm{DN})$ & 12 & $0,0006^{\mathrm{ns}}$ & $0,000001^{\mathrm{ns}}$ & $0,001^{\mathrm{ns}}$ & $2,041^{\mathrm{ns}}$ \\
\hline Bloco & 3 & $0,0007^{\mathrm{ns}}$ & $7,666^{\mathrm{ns}}$ & $0,006^{\mathrm{ns}}$ & $2,597^{\mathrm{ns}}$ \\
\hline $\mathrm{CV}(\%)$ & & 11,10 & 5,46 & 13,44 & 10,99 \\
\hline
\end{tabular}

$\mathrm{ns}, * *, *$ respectivamente não significativos, significativo a $\mathrm{p}<0,01$ e $\mathrm{p}<0,05$;

O incremento da condutividade elétrica na água de irrigação causou efeito linear decrescente sobre a taxa de crescimento absoluto da altura de planta no intervalo de 25 a 130 DAE (Figura 3A), com redução de 5,24\% por amento unitário da CEa. Nas plantas irrigadas com CEa de $3,5 \mathrm{dS} \mathrm{m}^{-1}$ ocorreu redução de $16,76 \%\left(0,036 \mathrm{~cm} \mathrm{dia}^{-1}\right)$ em comparação com as que receberam o menor nível de salinidade $(0,3 \mathrm{dS} \mathrm{m}$ $\left.{ }^{1}\right)$. Efeito semelhante foi observado por Torres et al. (2014) em mudas de cajueiro sob condições de estresse salino, em que verificaram decréscimo linear sobre a taxa de crescimento absoluto da altura de planta com o incremento da CEa.

Para Arruda et al. (2002), o excesso de sais na zona radicular causam, em geral, efeito deletério sobre as plantas, que se manifesta por redução na absorção de água, na taxa de fotossíntese e, consequentemente, no crescimento das plantas. Além disso, salienta-se que o efeito tóxico dos sais absorvidos pelas plantas, principalmente $\mathrm{Na}^{+}$e $\mathrm{Cl}^{-}$e a baixa capacidade de ajustamento osmótico das plantas à salinidade, também possam ter contribuído com a redução da velocidade de crescimento das plantas, a qual representada pela TCAap.

De acordo com a equação de regressão (Figura 3B) verifica-se que o aumento na dose de $\mathrm{N}$ causou efeito decrescente sobre a TCAap no período de 25-130 DAE, com redução de $0,045 \mathrm{~cm} \mathrm{dia}^{-1}(18,90 \%)$ nas plantas que receberam dose de $160 \%$ de $\mathrm{N}\left(1237 \mathrm{mg}^{\mathrm{de}} \mathrm{N} \mathrm{dm}^{-3}\right)$ em relação às plantas adubadas com $70 \%$ de $\mathrm{N}\left(541 \mathrm{mg} \mathrm{de} \mathrm{N} \mathrm{dm}^{-}\right.$ $\left.{ }^{3}\right)$. Observa-se (Figura 3) que a menor dose $(70 \%$ de N, ou

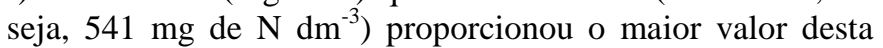
variável. Desse modo, ressalta-se que, desde que seja aplicada em quantidades adequadas, a fertilização nitrogenada atribui importância fundamental no crescimento das plantas (FLORES et al., 2001).
Figura 3: Taxa de crescimento absoluto da altura de planta TCAap de porta-enxerto de goiabeira de genótipo Crioula em função da condutividade elétrica da água de irrigação - CEa (A) e doses de nitrogênio no período de 25 a 130 DAE (B).
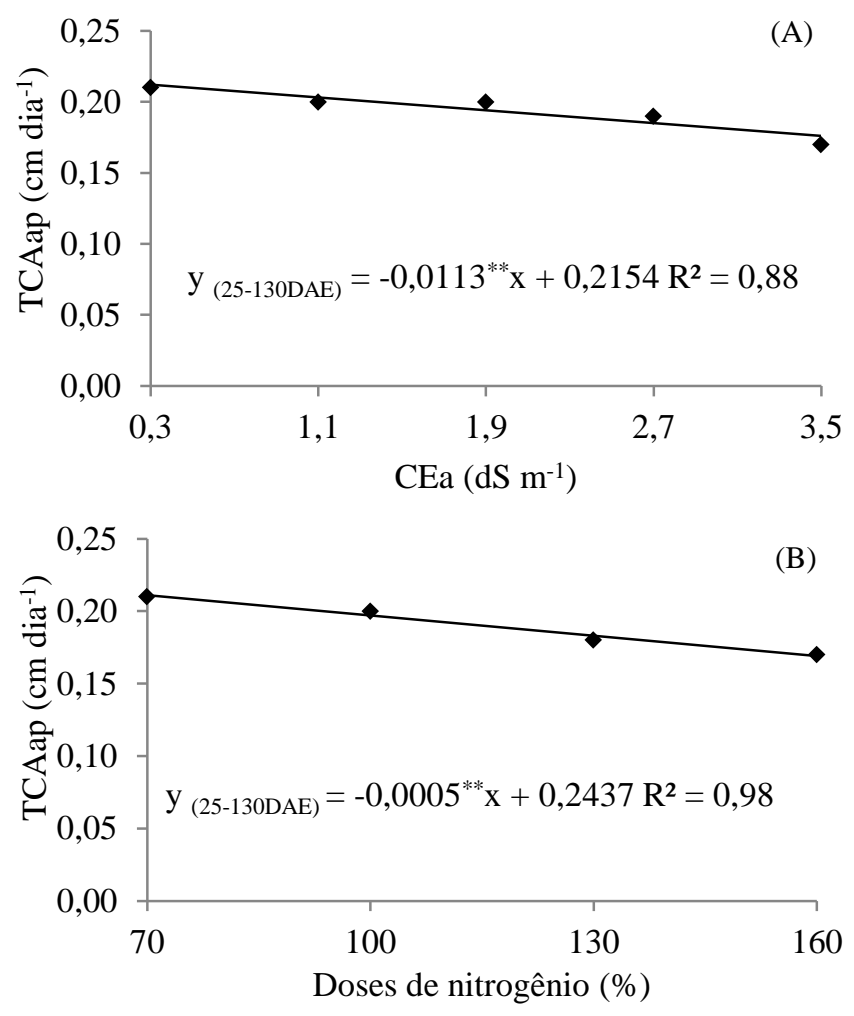

Constata-se segundo a equação de regressão (Figura 4A) que a TCRap durante o período de 25-130 DAE, sofreu redução linear de $2,77 \%$ por aumento unitário da $\mathrm{CEa}$, ou seja, as plantas irrigadas com condutividade de $3,5 \mathrm{dS} \mathrm{m}^{-1}$ apresentaram diminuição de $0,00025 \mathrm{~cm} \mathrm{~cm}^{-1} \mathrm{dia}^{-1}$ quando comparadas às plantas que receberam CEa de $0,3 \mathrm{dS} \mathrm{m}^{-1}$.

À medida que se aumenta o nível de salinidade, as plantas ficam expostas a um maior grau de retenção de água 
no solo pelo efeito osmótico dos sais, chegando a um ponto que não tenham energia suficiente para absorver água em proporção favorável às suas necessidades metabólicas (NOBRE et al., 2014), acarretando em reduções no crescimento.

$\mathrm{O}$ aumento da adubação nitrogenada causou efeito linear decrescente sobre a TCRap (Figura 4B), gerando perda de $3,0 \%$ para cada incremento de $30 \%$ na dose de N. O incremento na dose de $\mathrm{N}$ pode ter contribuído com elevação da acidez no substrato de cultivo pela ação da ureia utilizada como como fonte de $\mathrm{N}$, já que o desdobramento pela uréase libera $\mathrm{H}^{+}$(MALAVOLTA, 2006). Isto pode ter refletido sobre a disponibilidade de nutrientes, que afetou negativamente o crescimento das plantas.

Figura 4: Taxa de crescimento relativo da altura de planta TCRap de porta-enxerto de goiabeira de genótipo Crioula em função da condutividade elétrica da água de irrigação - CEa (A) e doses de nitrogênio no período de 25 a 130 DAE (B).


Para a relação altura/diâmetro do caule verifica-se, conforme equação de regressão (Figura 5A) que o incremento da condutividade elétrica da água de irrigação promoveu efeito linear crescente, com aumento de $5,94 \%$ por aumento unitário da CEa. Deduz-se que este aumente reflete negativamente sobre o porta-enxerto, uma vez que, representa o decréscimo do diâmetro em relação ao crescimento em altura com aumento da $\mathrm{CEa}$, e o DC é considerado uma das características mais analisadas em porta-enxertos no momento da enxertia (CHAVES et al., 2000).

De acordo com Gomes et al. (2002) o valor resultante da AP/DC exprime o equilíbrio de crescimento, e quanto maior o valor de AP/DC, menor será o equilíbrio entre estas variáveis, resultando em menor capacidade de sobrevivência das mudas no plantio definitivo em campo, devido a presença de menor diâmetro em relação à altura.
A RMF apresentou efeito linear crescente aos 190 DAE com aumento da condutividade elétrica da água, e de acordo com a equação de regressão (Figura 5B) o acréscimo foi de $7,57 \%$ por aumento unitário na CEa. A razão de massa da folha representa a fração de massa seca não exportada para o resto da planta (MAGALHÃES, 1979). Observa-se (Figura 5B) que o incremento da salinidade da água de irrigação a partir de $0,3 \mathrm{ds} \mathrm{m}^{-1}$ proporcionou o aumento de fitomassa na folha em relação a fitomassa total da planta (RMF), inferindose que ocorreu menor exportação de fitomassa da folha (considerada o centro de produção) para as demais partes da planta. Sugere que o estresse salino reduz a atividade fotossintética, havendo menor produção e direcionamento de compostos sintetizados para as outras partes da planta.

Figura 5: A razão de massa da folha (RMF) (A) e relação altura/diâmetro do caule (AP/DC) (B) de porta-enxerto de goiabeira em função da condutividade elétrica da água de irrigação - CEa 190 dias após a emergência DAE.
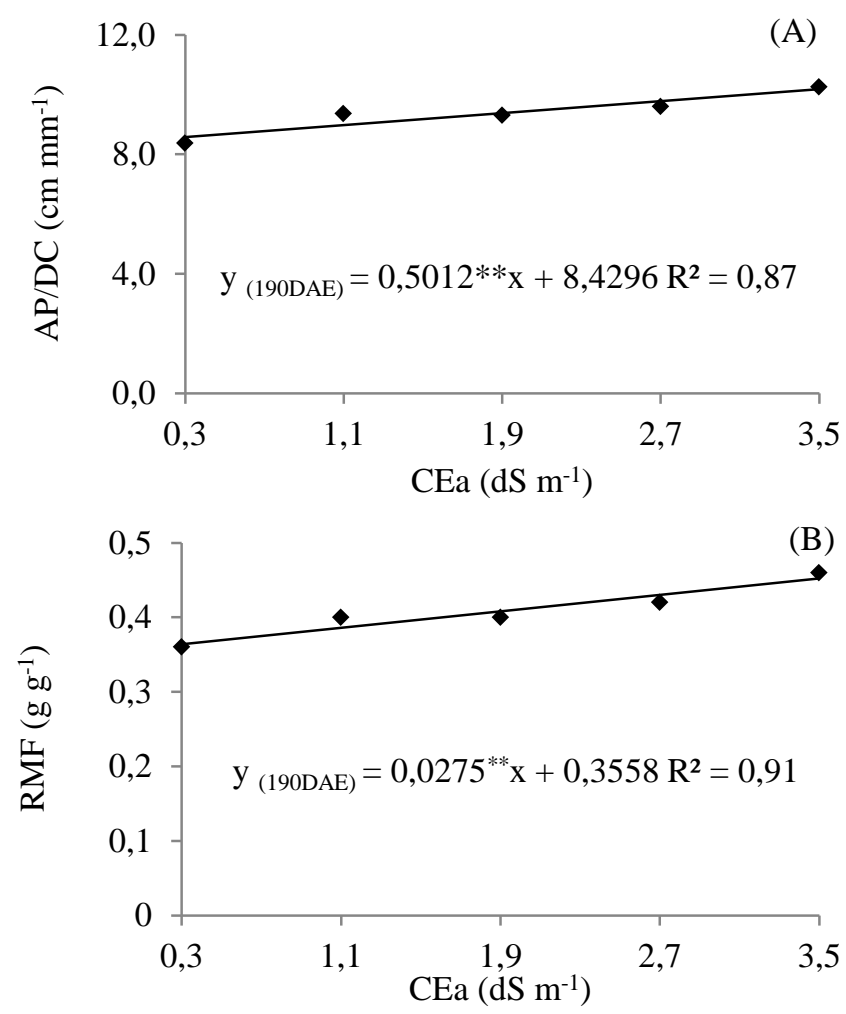

\section{CONCLUSÕES}

Não houve interação significativa entre os fatores salinidade da água de irrigação e adubação nitrogenada sob o crescimento de porta-enxerto de goiabeira de genótipo "Crioula".

$\mathrm{O}$ aumento da CEa a partir de $0,3 \mathrm{dS} \mathrm{\textrm {m } ^ { - 1 }}$ afeta negativamente e de forma linear o DC, NF, TCAap e TCRap, o equilíbrio de crescimento AP/DC e a exportação de massa seca da folha para o resto da planta (RMF).

A dose de $70 \%$ de $\mathrm{N}\left(541,1 \mathrm{mg}^{\mathrm{de}} \mathrm{N} \mathrm{dm}^{-1}\right.$ de solo) proporciona maiores valores do DC, NF, TCAap e TCRap de porta-enxerto de goiabeira "Crioula". 


\section{REFERÊNCIAS BIBLIOGRÁFICAS}

ARRUDA, F. P. et al. Efeito do estresse hídrico na emissão/abscisão de estruturas reprodutivas do algodoeiro herbáceo cv. CNPA 7H. Revista Brasileira de Engenharia Agrícola e Ambiental, Campina Grande, v. 6, n. 1, p. 21-27, 2002.

AYERS, R. S.; WESTCOT, D. W. A qualidade da água na agricultura. Campina Grande: UFPB, 1999. 218p.

BENINCASA, M. M. P. Análise de crescimento de plantas, noções básicas. 2 ed. Jaboticabal: FUNEP, 2003. 41 p.

CAVALCANTE, L. F. et al. Water salinity and initial development of four guava (Psidium guajava L.) cultivar in north-eastern Brazil. Journal of Fruit and Ornamental Plant Research, Skierniewice, v. 15, p. 71-80, 2007

CAVALCANTE, L. F; VIEIRA, M. S.; SANTOS, A. F.; OLIVEIRA, W. M.; NASCIMENTO, J. A. M. Água salina e esterco bovino líquido na formação de mudas de goiabeira cultivar Paluma. Revista Brasileira de Fruticultura, v.32, n.1, p. 251-261, 2010.

CHAVES, J. C. M. CAVALCANTI JÚNIOR, A. T.; CORREIA, D.; SOUZA, F. X.; ARAÚJO, C. A. T. Normas de produção de mudas. Fortaleza: Embrapa Agroindústria Tropical, 2000. 37p. (Documentos, 41).

CLAESSEN, M. E. C. (org.). Manual de métodos de análise de solo. 2.ed. Rio de Janeiro: Embrapa CNPS, 1997. 212p. Documentos, 1

DIAS, M. J. T.; SOUZA, H. A.; NATALE, W.; MODESTO, V. C.; ROZANE, D. E. Adubação com nitrogênio e potássio em mudas de goiabeira em viveiro comercial. Ciências Agrárias, v. 33, p. 2837-2848, 2012.

FLORES, P.; CARVAJAL, M.; MARTINEZ, V. Salinity and ammonium/nitrate interactions on tomato plant development, nutrition, and metabolites. Journal of Plant Nutrition, Oxford, v. 24, n. 10, p. 1561-1573, 2001.

FRANCO, F. C. et al. Curva de crescimento e marcha de absorção de macronutrientes em mudas de goiabeira. Revista Brasileira de Ciência do Solo, v. 31, n. 6, p. 1429-1437, 2007.

FREIRE, A. L. de O; SARAIVA, V. P; MIRANDA, J. R. P. de; BRUNO, G. B. Crescimento, acúmulo de íons e produção de tomateiro irrigado com água salina. Semina: Ciências Agrárias, Londrina, v. 31, suplemento 1, p. 1133-1144, 2010

GOMES, E. W. F. Variedades de bananeira tratadas com água salinizada em fase inicial de crescimento. Revista Brasileira de Engenharia Agrícola e Ambiental, Campina Grande, v. 9, p. 31-36, 2005. Suplemento.

GOMES, J. M.; COUTO, L.; LEITE, H. G. XAVIER, A.; GARCIA, S. L. R. Parâmetros morfológicos na avaliação da qualidade de mudas de Eucalyptus grandis. Revista Árvore, v.26, n.6, p.655-664, 2002.

GONZAGA NETO, L. Goiaba: produção - aspectos técnicos. Embrapa Semiárido, Brasília: Embrapa
Informações Tecnologias, 2001. 79p. Frutas do Brasil, 17.

MAGALHÃES, A. C. N. Análise quantitativa do crescimento. In: FERRI, M.G. Fisiologia Vegetal. EPU/EDUSP, São Paulo. 1979. v. 1, p. 331-350.

MALAVOLTA, E. Manual de nutrição mineral de plantas. São Paulo: Agronômica Ceres, 2006. 638 p.

MEDEIROS, J. F de. Qualidade de água de irrigação e evolução da salinidade nas propriedades assistidas pelo GAT nos Estados de RN, PB e CE. Campina Grande:Universidade Federal da Paraíba, 1992.173p. Dissertação Mestrado.

NOBRE, R. G.; LIMA, G. S de.; GHEYI, H. R.; SOARES, L. A. dos A., SILVA, A. O. da., Crescimento, consumo e eficiência do uso da água pela mamoneira sob estresse salino e nitrogênio. Revista Caatinga, Mossoró, v. 27, n. 2, p. $148-158,2014$

OLIVEIRA, F. A. de; OLIVEIRA FILHO, A. F. de; MEDEIROS, J. F. de; ALMEIDA JUNIOR, A. B.; LINHARES, P. C. F. Desenvolvimento inicial da mamoneira sob diferentes fontes e doses de matéria orgânica. Revista Caatinga, Mossoró, v. 22, n. 1, p. 206-211, 2009.

RHOADES, J. D.; KANDIAH, A.; MASHALI, A. M. Uso de águas salinas para 204 produção agrícola. UFPB, 2000, 117p. Estudos da FAO, Irrigação e Drenagem, 48, 205 revisado.

SIQUEIRA, E. da C.; GHEYI, H. R.; BELTRÃO, N. E. de M.; SOARES, F. A. L.; BARROS JÚNIOR, G.; CAVACALTI, M. L. F. Crescimento do algodoeiro colorido sob diferentes níveis de salinidade da água de irrigação. Revista Brasileira de Engenharia Agrícola e Ambiental, v.9, (Suplemento), p.263-267, 2005.

TÁVORA, F. J. A. F.; FERREIRA, R. G.; HERNANDEZ, F. F. F. Crescimento e relações hídricas em plantas de goiabeira submetidas a estresse salino com $\mathrm{NaCl}$. Revista Brasileira de Fruticultura, Jaboticabal, v.23, n.2, p.441-446, 2001.

TORRES, E. C. M.; FREIRE, J. L. O.; OLIVEIRA, J. L.; BANDEIRA, L. B.; MELO, D. A.; SILVA, A. L. Biometria de mudas de cajueiro anão irrigadas com águas salinas e uso de atenuadores do estresse salino. Nativa, Sinop, v.2, n.2, p.71-78, 2014. 